\title{
Gastric perforation during ligation-assisted endoscopic mucosal resection of a neuroendocrine tumor: banding without resection may be a safer option
}

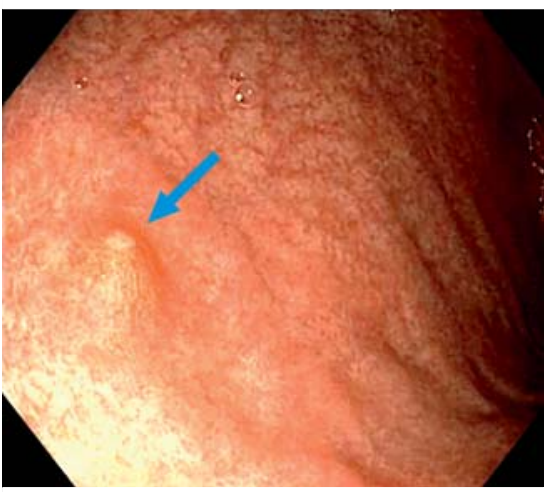

Fig. 1 Endoscopic view of one (arrow) of the three neuroendocrine tumors.

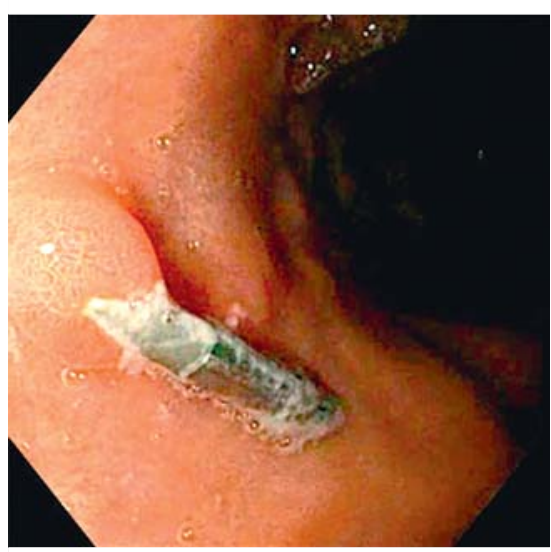

- Fig.4 Remaining clip in the fibrous scar of the first resected neuroendocrine tumor.

The management of small gastrointestinal subepithelial tumors (SETs) considers periodic endoscopic surveillance vs. endoscopic removal for entities with malignant potential such as neuroendocrine tumor (NET), gastrointestinal stromal tumor or others [1]. Excision by ligationassisted endoscopic mucosal resection (EMR) is an option for small SETs [2].

In a 57-year-old woman undergoing periodic endoscopic surveillance for chronic atrophic gastritis, three small grade 2 (Ki-67, 3\%) NETs were identified in the gastric body ( $>$ Fig. 1). Indication for en-

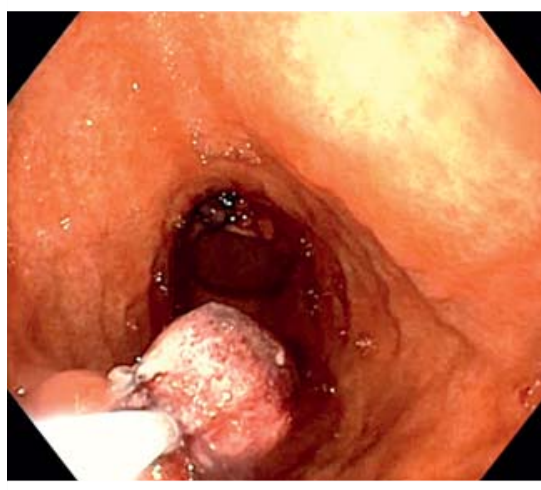

- Fig. 2 Neuroendocrine tumor resection with electrocautery snare after band ligation.

doscopic excision was agreed by consensus in a multidisciplinary committee. EMR using a specific mucosectomy device (Captivator; Boston Scientific, Quincy, Massachusetts, USA) was proposed. During NET banding, two technical incidents occurred: 1) the transparent cap of the device was not optimally attached to the tip of the gastroscope (the blue rubber bands should not be observed in the endoscopic view); and 2) two bands, instead of one, were deployed when the first NET was ligated. During resection of the first NET using an electrocautery snare (ERBE, $40 \mathrm{~W}$ cut, $30 \mathrm{~W}$ coagulation; ERBE Elektromedizin $\mathrm{GmbH}$, Tübingen, Germany), immediate gastric perforation occurred ( $>$ Fig. 2). The wall defect was effectively closed during the same procedure by endoscopic clipping using eight clips (Resolution clip; Boston Scientific) ( $\triangleright$ Fig.3). Endoscopic band ligation (EBL) without resection was decided for the other two NETs, avoiding the resection technique.

The patient did well after the procedure, requiring a 7-day hospital stay. Endoscopic surveillance after 10 months and 2 years showed a fibrous scar and one remaining clip from the first resected NET (pathological biopsy examination

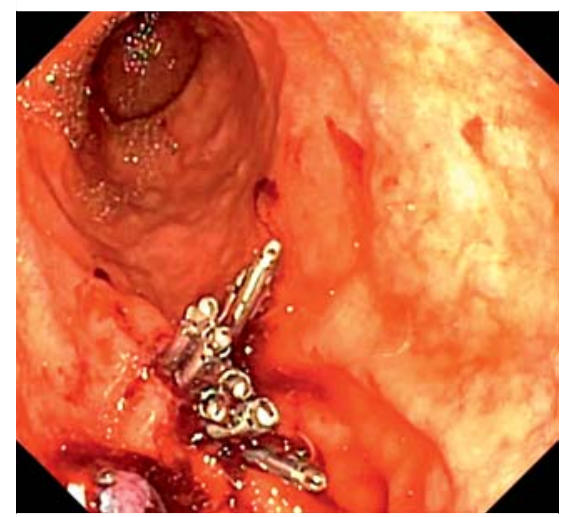

- Fig. 3 Wall defect closure by endoscopic clipping.

confirmed fibrous tissue) ( $\triangleright$ Fig. 4 ), and the disappearance of the other two NETs ( Video 1).

Ligation-assisted EMR is associated with a non-negligible rate of adverse events such as perforation [2,3]. EBL without resection is an apparently safe and effective option for management of small SETs $[4,5]$.

Endoscopy_UCTN_Code_TTT_1AO_2AC

\section{Competing interests}

Joan B Gornals is a consultant for Boston Scientific.

The authors

Francesc Bas-Cutrina ${ }^{1}$, Raquel Ballester-Clau ${ }^{2}$, Ferran González-Huix ${ }^{2}$, Joan B. Gornals ${ }^{1,3}$

1 Endoscopy Unit, Department of Digestive Diseases, Hospital Universitari de Bellvitge IDIBELL, University of Barcelona, Barcelona, Spain

2 Endoscopy Unit, Department of Digestive Diseases, Hospital Universitari Arnau de Vilanova de Lleida, Lleida, Spain

3 Faculty of Health Sciences, Universitat Oberta de Catalunya, Barcelona, Spain 


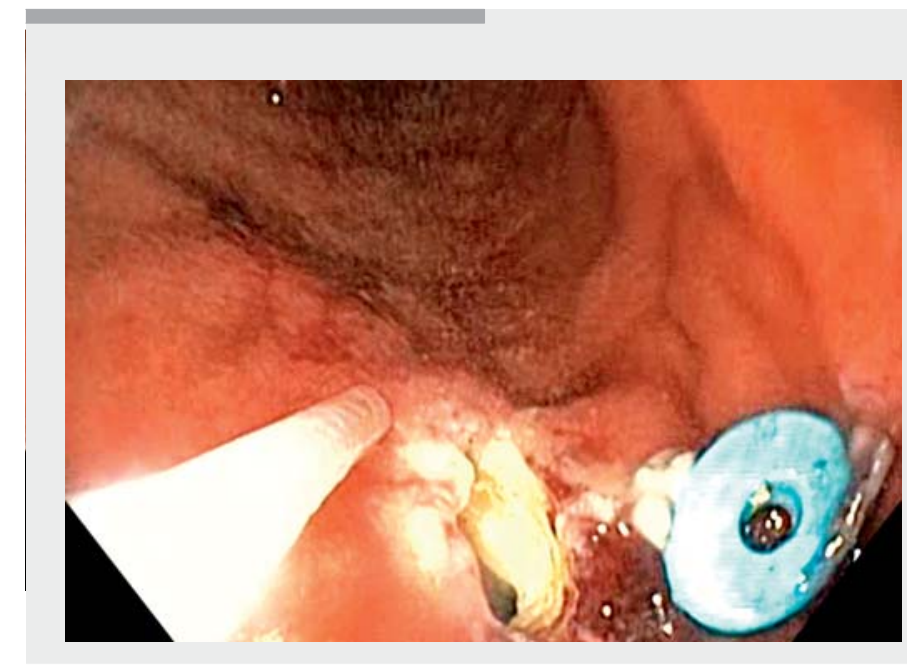

Video 1 Intraprocedure adverse event during ligation-assisted endoscopic mucosal resection: gastric perforation.

\section{Joan B. Gornals, MD, PhD}

Endoscopy Unit, Department of Digestive Diseases, Hospital Universitari de Bellvitge IDIBELL (Bellvitge Biomedical Research Institute), Feixa Llarga s/n, L'Hospitalet de Llobregat, Barcelona, 08907 Catalonia, Spain Fax: +34-93-2607681

jgornals@bellvitgehospital.cat

\section{References}

[1] Faulx AL, Kothari S, Acosta RD et al. The role of endoscopy in subepithelial lesions of the GI tract. Gastrointest Endosc 2017; 85: $1117-1132$

[2] Hwang JH, Konda V, Abu Dayyeh BK et al. Endoscopic mucosal resection. Gastrointest Endosc 2015; 82: 215-226

[3] Zang D, Lin Q, Shi R et al. Ligation-assisted endoscopic submucosal resection with apical mucosal incision to treat gastric subepithelial tumors originating from the muscularis propria. Endoscopy 2018; 50: 1180 1185
[4] Binmoeller KF, Shah JN, Bhat YM et al. Suckligate-unroof-biopsy by using a detachable 20-mm loop for the diagnosis and therapy of small subepithelial tumors (with video). Gastrointest Endosc 2014; 79: 750-755

[5] Bas-Cutrina F, Consiglieri CF, Bosch-Schips ] et al. Endoscopic band ligation plus singleincision needle-knife biopsy for small subepithelial deep-layer tumor: easy and effective. Endoscopy 2019; 51: E191-192

\section{Bibliography}

DOI https://doi.org/10.1055/a-1134-4742

Published online: 27.3.2020

Endoscopy 2020; 52: E370-E371

(c) Georg Thieme Verlag KG

Stuttgart · New York

ISSN 0013-726X

\section{ENDOSCOPY E-VIDEOS \\ https://eref.thieme.de/e-videos}

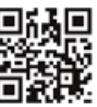

Endoscopy E-Videos is a free access online section, reporting on interesting cases and new

techniques in gastroenterological endoscopy. All papers include a high quality video and all contributions are freely accessible online.

This section has its own submission website at https://mc.manuscriptcentral.com/e-videos 